\title{
"Uma força que atrai": o significado das drogas para usuários de uma ilha de Cabo Verde
}

\author{
Augusto César Lima Neves ${ }^{1}$ \\ Adriana Inocenti Miasso ${ }^{2}$
}

Este estudo teve como objetivo compreender o significado do consumo de drogas na perspectiva de usuários, atendidos em um ambulatório do Serviço da Saúde Mental de uma ilha do arquipélago de Cabo Verde. Dada a natureza do problema, esta investigação utilizou a abordagem qualitativa, tendo como referencial metodológico a Teoria Fundamentada nos Dados, à luz do Interacionismo Simbólico. Participaram do estudo nove usuários de drogas do referido ambulatório. A entrevista gravada e a observação foram as estratégias de obtenção de dados. A análise comparativa dos dados resultou no fenômeno central "uma força que atrai", expressando a grande dificuldade que os usuários têm para se afastar do consumo abusivo de substâncias psicoativas, sabendo, previamente, que todos os problemas enfrentados nas esferas pessoal, familiar e social advêm da habituação. Este estudo permitiu, assim, identificar pontos vulneráveis de possível atuação da equipe de saúde, visando a prevenção do abuso de drogas.

Descritores: Drogas Ilícitas; Relações Interpessoais; Saúde Pública.

\footnotetext{
${ }^{1}$ Psicólogo Especializado em Psicologia da Saúde, Serviço de Saúde Mental, Hospital Baptista de Sousa, S. Vicente, Cabo Verde. E-mail: gugass62@yahoo.com.br.

${ }^{2}$ Enfermeira, Doutor em Enfermagem, Professor Doutor, Escola de Enfermagem de Ribeirão Preto, Universidade de São Paulo, Centro Colaborador de la OMS para el Desarrollo de la Investigación en Enfermería, SP, Brasil E-mail: amiasso@eerp.usp.br
}

\footnotetext{
Correspondencia:

Adriana Inocenti Miasso

Universidade de São Paulo. Escola de Enfermagem de Ribeirão Preto

Av. Bandeirantes, 3900

Bairro Monte Alegre

CEP: 14040-902 Ribeirão Preto, SP, Brasi

E-mail: amiasso@eerp.usp.br
} 


\section{"Una fuerza que atrae": el significado de las drogas para usuarios de una Isla de Cabo Verde}

Ese estudio cualitativo tuvo como objetivo comprender el significado del consumo de drogas desde la perspectiva de usuarios atendidos en una clínica del Servicio de Salud Mental de una isla del archipiélago de Cabo Verde. La investigación tuvo como referencial metodológico la Teoría Fundamentada en los Datos, bajo la interpretación del Interaccionismo Simbólico. Participaron del estudio nueve usuarios de drogas de la referida clínica. La grabación de la entrevista y su observación fueron las estrategias para obtener los datos. El análisis comparativo de los datos mostró como resultado el fenómeno central "Una fuerza que atrae", que expresa la gran dificultad que los usuarios tienen para alejarse del consumo abusivo de substancias psicoactivas, sabiendo, previamente, que todos los problemas enfrentados en las esferas personal, familiar y social provienen de la drogadicción. Este estudio permitió, así, identificar puntos vulnerables en los cuales podría actuar el equipo de salud con la finalidad de prevenir el abuso de drogas.

Descriptores: Drogas Ilícitas; Relaciones Interpersonales; Salud Pública.

\section{"An Attractive Force": The Meaning of Drugs to Users From an Island in Cape Verde}

This qualitative study aimed to understand the meaning of drug consumption from the view of users who receive care in an outpatient clinic of a Mental Health Service on an island of the Cape Verde archipelago. The methodological framework was based on the Data-founded Theory, in the light of Symbolic Interactionism. Participants were nine drug users from the mentioned outpatient clinic. Recorded interviews and observation were the strategies for data collection. The comparative data analysis resulted in the central phenomenon "An attractive force", which expresses the great difficult users have to stop the abusive consumption of psychoactive substances, knowing that all problems faced in the personal, familiar and social areas come from drug habituation. Thus, this study permitted the identification of vulnerable points for possible action by the health team, aiming for the prevention of drug abuse.

Descriptors: Street Drugs; Interpersonal Relations; Public Health.

\section{Introdução}

O consumo de substâncias que possuem a capacidade de alterar a consciência e modificar o comportamento parece ser um fenômeno da humanidade. Praticamente em todas as culturas e nas mais diferentes épocas, são eleitas determinadas substâncias desse tipo (ou grupos delas) que auxiliam no relacionamento social, marcam festividades, ou favorecem rituais de cunho místico/ religioso.

Desse modo, o uso de substâncias psicoativas encontra-se profundamente enraizado nas tradições socioculturais de muitas sociedades. A esse respeito, a literatura evidencia que, nas últimas décadas, houve aumento assustador da frequência do uso de drogas no mundo, sejam elas nas suas formas lícitas ou ilícitas. O consumo passou de pequenas quantidades, para a produção, consumo e distribuição em grande escala, como um produto comerciall ${ }^{(1)}$, tornando-se sério problema de saúde pública.

No que se refere às drogas ilícitas, seus usuários já somam mais de 185 milhões em todo o mundo(2). Uma das principais preocupações dos países, tanto de modo individual como das organizações internacionais( ${ }^{(3)}$, são os problemas resultantes de seu uso e, por esse motivo, o uso e abuso de drogas passam a ser tema primordial na agenda nacional e internacional. 
São descritas como possíveis razões para o início do uso de substâncias psicoativas: o surgimento de uma oportunidade e a escolha pela experimentação por parte do jovem, o poder de transformação das emoções que a droga possibilita, o imaginário de que o uso de drogas é excitante e ousado, a influência do grupo no consumo de drogas, a tentativa para minimizar sentimentos de solidão, baixa autoestima ou falta de confiança; bem como toda uma imposição, pela sociedade, de felicidade para as pessoas, sem considerar que a abstração das frustrações é parte integrante da vida, devendo ser compreendida e transformada(4).

As consequências na vida do indivíduo, decorrentes do uso de drogas, são inúmeras e muito graves. Além de contribuir para o crescimento dos gastos com tratamentos médicos e internações hospitalares, aumenta os índices de acidentes de trânsito, de violências urbanas, de mortes prematuras e suicídios ${ }^{(5-6)}$.

Desse modo, o consumo inadequado de drogas tem acarretado problemas sociais, econômicos e de saúde de grande importância em todas as culturas, de forma geral, e, em Cabo Verde, de forma particular. A amplitude e gravidade desses problemas exigem estudos e políticas específicas para o seu enfrentamento, além de investimentos maiores nessa área, visto que suas consequências vêm se multiplicando de forma generalizada e preocupante. Em Cabo Verde, a gravidade das consequências do uso e abuso das drogas é potencializada pelas precárias condições socioeconômicas da população, pelo baixo preço de tais substâncias, facilidade na sua obtenção, bem como pela atitude permissiva da população.

Vários estudos têm sido desenvolvidos, mundialmente, visando obter soluções para o problema do uso e abuso de drogas ilícitas, todavia, esses estão focados, frequentemente, na perspectiva de profissionais de saúde, de políticos ou de instituições oficiais, e não sob a ótica do próprio usuário ou de pessoas próximas aos mesmos(7). Tal aspecto é relevante, pois, quando uma pessoa ingere uma droga, sua experiência posterior é influenciada por suas ideias e crenças sobre aquela substância(8).

Considerando a complexidade dos fatores envolvidos no uso e abuso das drogas ilícitas, fazse importante sua compreensão a partir das diversas relações singulares que os indivíduos estabelecem com a substância, ao longo da vida. Desse modo, foi objetivo deste estudo compreender o significado do consumo de drogas sob a perspectiva de usuários atendidos em um ambulatório do Serviço da Saúde Mental, de uma ilha do arquipélago de Cabo Verde. Acredita-se que um estudo desta natureza forneça subsídios para a implementação de estratégias preventivas e outras que minimizem as consequências do abuso e dependência de drogas para indivíduos, famílias e sociedade.

\section{Metodologia}

Trata-se de estudo transversal, descritivo, de natureza qualitativa. Foi desenvolvido no ambulatório do Serviço da Saúde Mental do Hospital Dr. Baptista de Sousa, localizado na ilha de S. Vicente, arquipélago de Cabo Verde, após autorização do Comitê Nacional de Ética para Pesquisa em Saúde (CNEPS) do referido país (Deliberação 4/2008). Optou-se por esse local de estudo por atender usuários de drogas não internados em instituições de assistência, porém, necessitando de atenção e acompanhamento.

Constituíram critérios de inclusão do estudo: ter diagnóstico médico de dependência química, idade igual ou superior a 18 anos, estar apto a se expressar verbalmente e consentir, por escrito, em participar do estudo (assinar o termo de consentimento livre e esclarecido). Foram excluídos do estudo todos os pacientes que não preenchiam esses critérios de inclusão. Por ser estudo de natureza qualitativa, o número de participantes não foi predeterminado, mas resultou de um processo de amostragem teórica ou proposital, que faz parte da metodologia utilizada. Foi também utilizada a técnica da amostragem por bola-de-neve, quando os entrevistados indicaram o nome de novas pessoas a serem entrevistadas.

A entrevista gravada e a observação participante foram utilizadas como estratégias de obtenção de dados. A entrevista semiestruturada teve como questão inicial para o participante Conte-me sobre como é para você usar ou consumir drogas. A questão norteadora apenas direcionou os pontos do estudo a serem explorados. Novas questões foram acrescentadas, a partir da exposição dos sujeitos do estudo, com o intuito de esclarecer e fundamentar a experiência por eles descrita. A análise dos dados foi embasada, metodologicamente, na Teoria Fundamentada nos Dados (TFD), à luz do Interacionismo Simbólico. Considerando-se que a premissa básica da TFD é a comparação constante entre os dados, a coleta e a análise dos mesmos caminharam paralelamente. Desse modo, o primeiro passo dessa análise foi a própria transcrição dos dados, seguida pela codificação dos mesmos(9). 
Os procedimentos de codificação são apresentados em três etapas que se complementam: codificação aberta, codificação axial e codificação seletiva(9). A codificação aberta é a parte da análise que se refere, especificamente, a nominar e categorizar fenômenos por meio do exame minucioso dos dados, linha por linha, parágrafo por parágrafo ${ }^{(9)}$. A comparação dos códigos entre si deu origem às categorias, as quais foram integradas por meio da codificação axial. Essa foi realizada seguindo o paradigma de codificação, proposto por Strauss e Corbin ${ }^{(9)}$, envolvendo: a causa desencadeadora do fenômeno, o contexto em que o mesmo está inserido, as condições intervenientes, as estratégias de ação sobre o fenômeno e suas consequências. A codificação seletiva deu origem à categoria central "uma força que atrai". Nessa fase, todos os conceitos e categorias foram sistematicamente relacionados à categoria central e, a partir daí, foi realizada a análise de suas relações.

Para que fosse preservado o anonimato dos participantes do estudo, optou-se por identificá-los por letras do alfabeto.

\section{Resultados}

Participaram deste estudo nove usuários de drogas, todos do sexo masculino, com idade de 23 a 46 anos.

Identificou-se que sete dos pacientes entrevistados eram solteiros e dois divorciados (que se separaram em consequência do uso da droga), e a maioria possuía ensino médio incompleto. O tempo de diagnóstico variou de dois a 24 anos, e todos já foram internados, no mínimo uma vez, em enfermaria de psiquiatria, e realizavam seguimento no ambulatório do serviço de saúde mental. Verificou-se, ainda, que todos os pacientes utilizavam cocaína e erva, sendo que dois deles usavam, também, a heroína. Vale destacar que, no momento da entrevista, nenhum paciente possuía vínculo empregatício. Dentre os pacientes, cinco foram demitidos do último emprego por causa da droga (um era policial, três eram condutores profissionais de carros de transporte pesado e um trabalhava em estabelecimento comercial), e os outros quatro tinham trabalhos esporádicos.

\section{Desvelando o fenômeno}

Uma vez iniciado o processo de aglomeração das categorias e subcategorias, de acordo com o paradigma de análise de dados, proposto por Strauss e Corbin ${ }^{(8)}$, em termos de contexto, condições causais, consequências, estratégias de ação e condições intervenientes, emergiu o fenômeno "uma força que atrai" como eixo principal dessa integração. O referido fenômeno evidencia a grande dificuldade que os usuários têm para se afastar do consumo abusivo de substâncias psicoativas, sabendo, previamente, que todos os problemas enfrentados nas esferas pessoal, familiar e social advêm da habituação.

O uso abusivo de drogas constitui, sem dúvida, um fenômeno complexo. O dependente, frente às dificuldades cotidianas, encontra na droga um caminho quimicamente efetivo para superar a sua fragilidade e supostamente evitar a desintegração do seu ego. Ao atribuir significado ao uso da droga, surge uma categoria simbólica com fundamento místico - "uma força que atrai", considerada maligna, que vicia, que controla seu usuário. Por meio dos depoimentos de pacientes e à luz da sua própria cultura e costumes, o conteúdo místico e simbólico do fenômeno é refletido.

... tem algo maligno que nos puxa para usar mais, é tipo uma força maligna que é irresistível, mas explicar essa coisa é difícil (D).

... droga é mais forte do que nós porque entrar na droga é fácil, mas sair dela é difícil só com ajuda (C).

... eu uso como um vício, é só no momento é como um aço que atrai (E).

... muitas vezes é como uma "intentação" mesmo que quero comprar outras coisas, mas não consigo... depois é como se fosse ela a controlar-me se tenho dinheiro é como se me chamasse... é como se diabo estivesse junto de mim (F).

Constata-se, assim, que a manutenção do fenômeno implica o continuar em um padrão de uso abusivo da droga, pois, mesmo com o conhecimento das consequências e dos riscos, o consumo persiste. A seguir, serão apresentadas as diversas categorias relacionadas ao fenômeno "uma força que atrai". As categorias e subcategorias estão integradas ao fenômeno central e apresentadas em termos de condições causais, contexto, estratégias de ação, condições intervenientes e consequências, de acordo com o paradigma de codificação.

\section{Paradigma da codificação}

\section{Contexto}

O contexto descrito pelo usuário de drogas reflete sua dificuldade em se afastar das mesmas, apesar de conhecer sua periculosidade, como evidenciam as categorias da figura a seguir. 


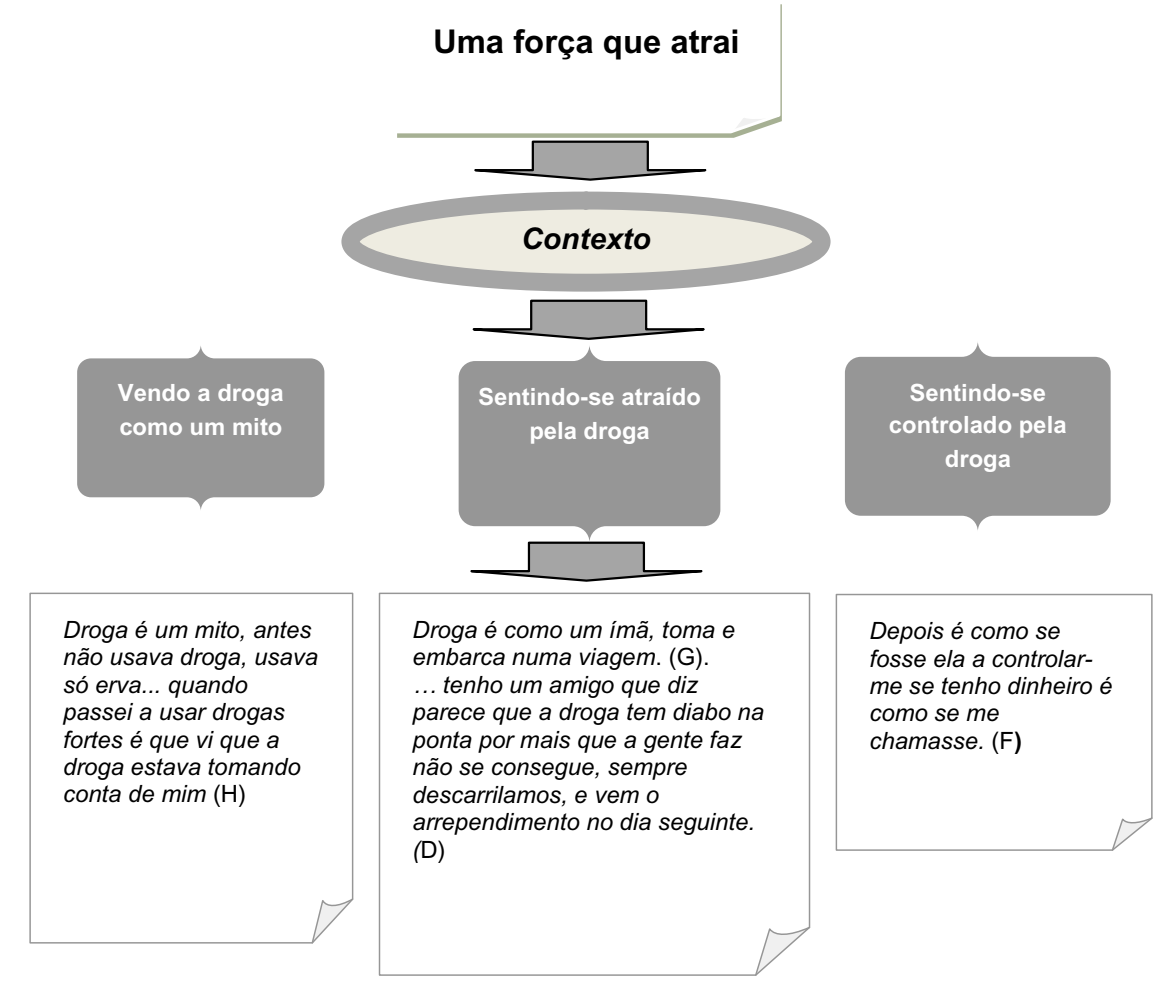

Figura 1 - Diagrama do contexto do fenômeno "uma força que atrai"

\section{Condições causais}

As categorias "começando a usar em grupo", "usando para esquecer os problemas" e "sentindo-se mais leve quando usa" representam, de acordo com os depoimentos dos participantes do estudo, as causas que desencadeiam o fenômeno "uma força que atrai". Essas causas são os elementos que potencializam a dependência, tornando-se, em grande parte das vezes, incontroláveis para o dependente.

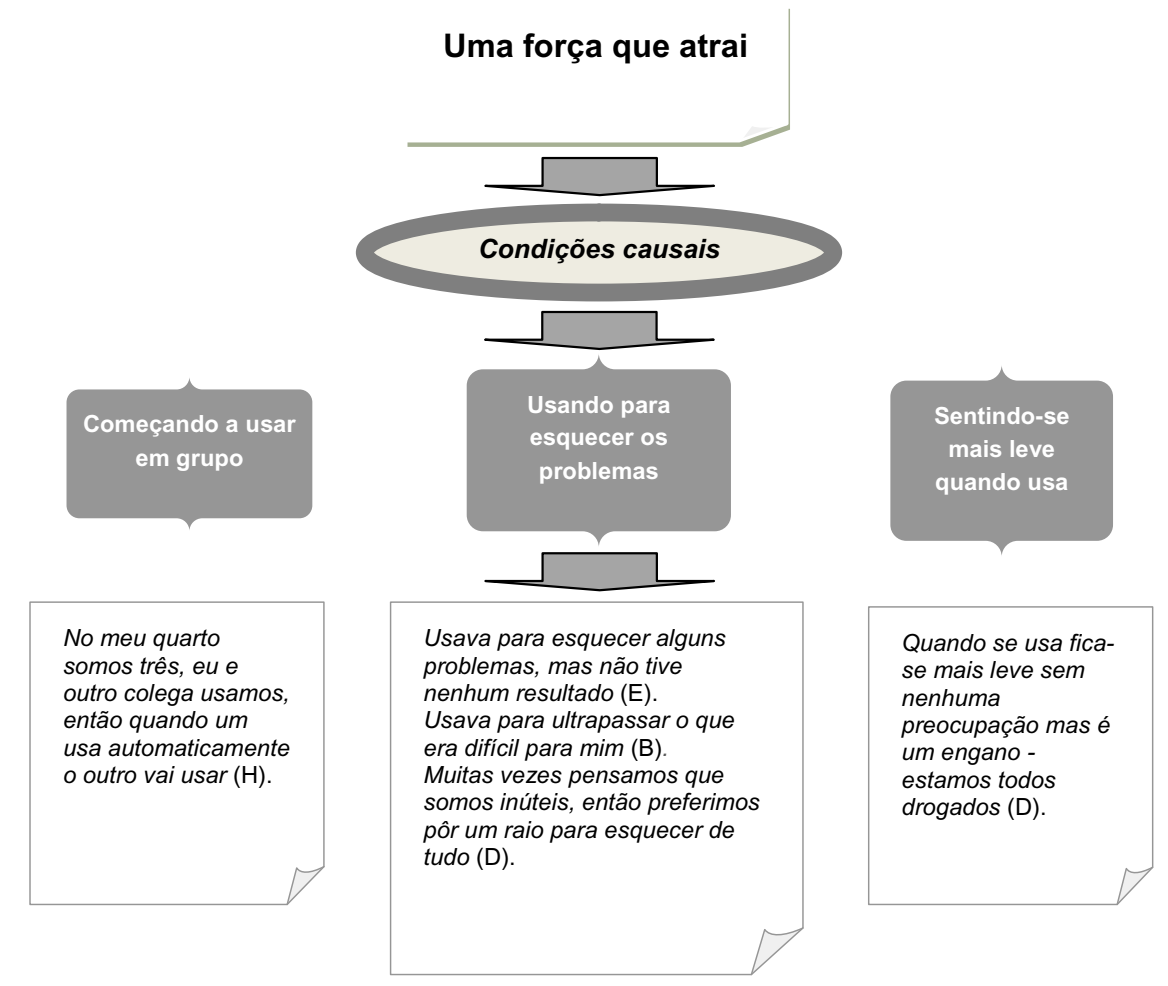

Figura 2 - Diagrama das condições causais do fenômeno "uma força que atrai" 


\section{Consequências}

As categorias que compõem as consequências do fenômeno revelam que, por não conseguir se afastar das drogas, o usuário vivencia perdas em várias esferas de seu cotidiano. Seus depoimentos revelam perdas afetivas, especialmente nas relações com

amigos e familiares; perdas financeiras, evidenciadas pelo desemprego e gastos com a compra da substância e perda da autoestima ao recair após o tratamento e se perceber dominado pela droga.

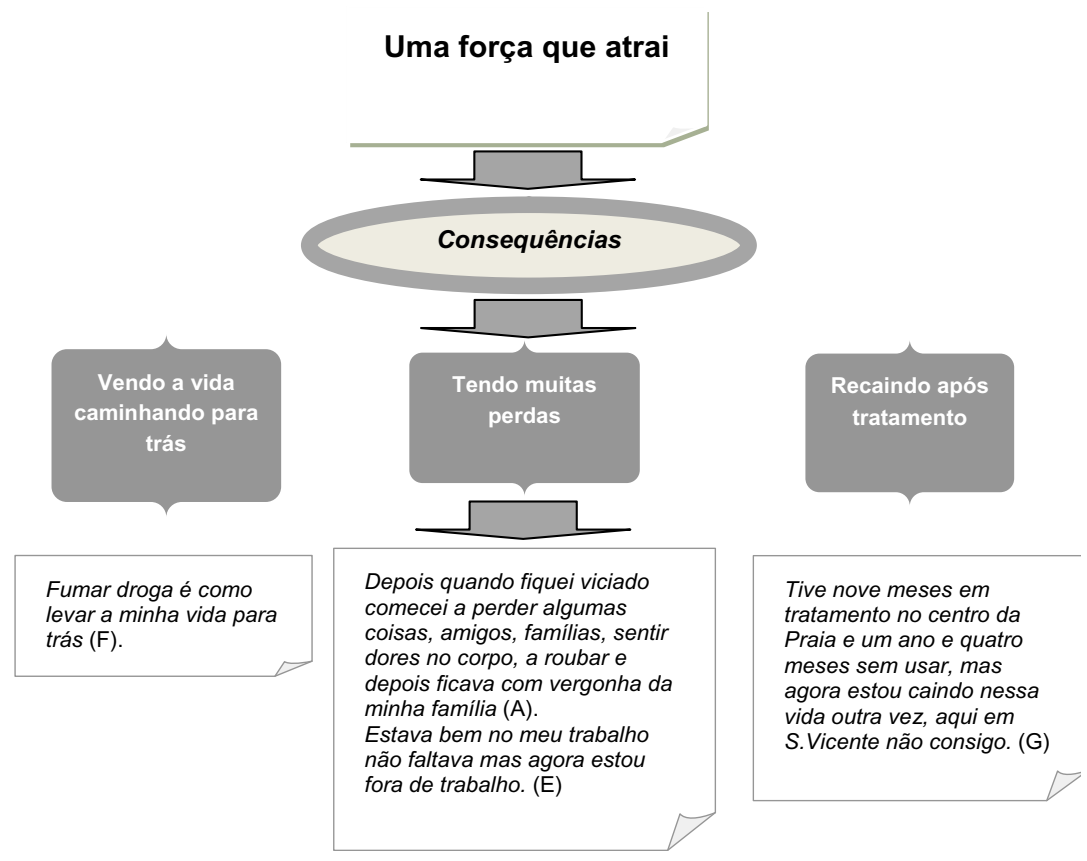

Figura 3 - Diagrama das consequências do fenômeno "uma força que atrai"

\section{Condições intervenientes}

As categorias que representam as condições intervenientes revelam aspectos que fortificam (falta de apoio da sociedade e da família, principalmente dos pais) e/ou abrandam (apoio de amigos e familiares) o impacto das condições causais do fenômeno "uma força que atrai" e explicam o porquê da dificuldade para abandonar o hábito.

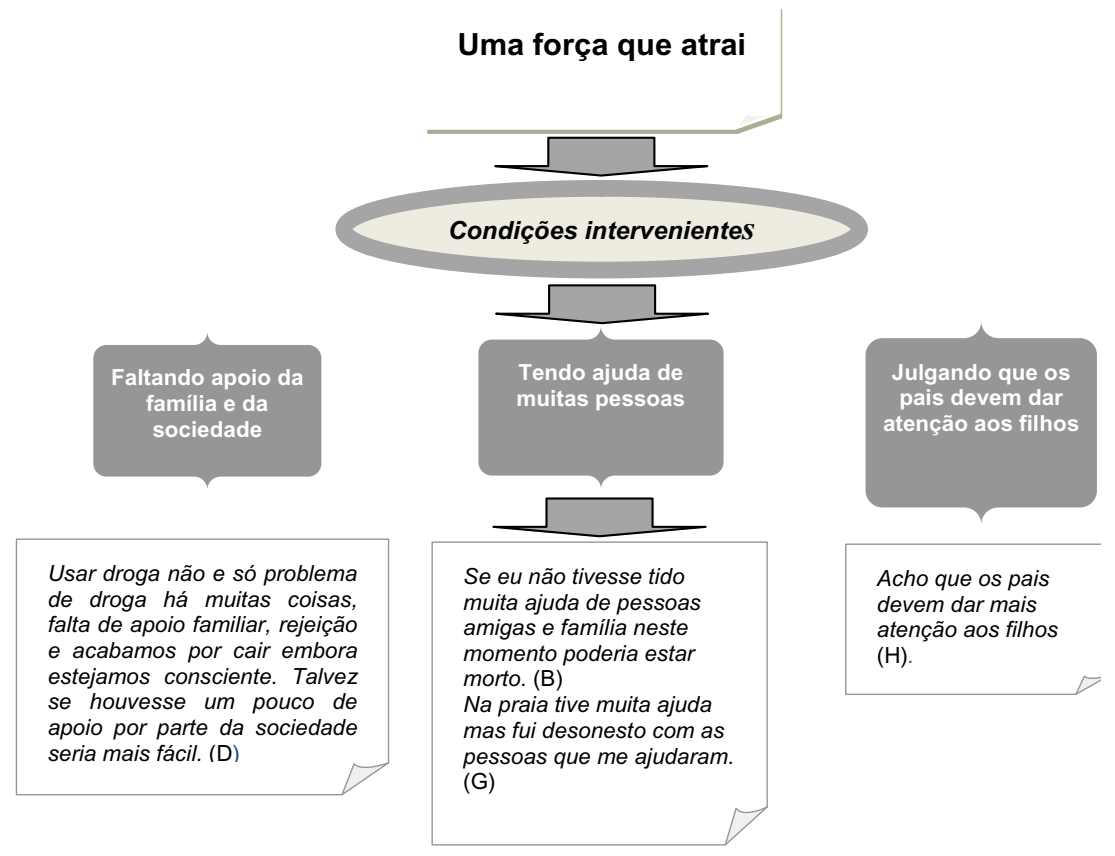

Figura 4 - Diagrama das condições intervenientes do fenômeno "uma força que atrai" 


\section{Estratégias de ação}

As estratégias mostram como o usuário de drogas, a partir de suas motivações internas e externas, movimentase frente ao que é vivenciado e experimentado em sua cotidianidade. Toma, assim, decisões acerca do que fazer e de como agir para modificar aspectos negativos de sua realidade, como revela a figura a seguir.

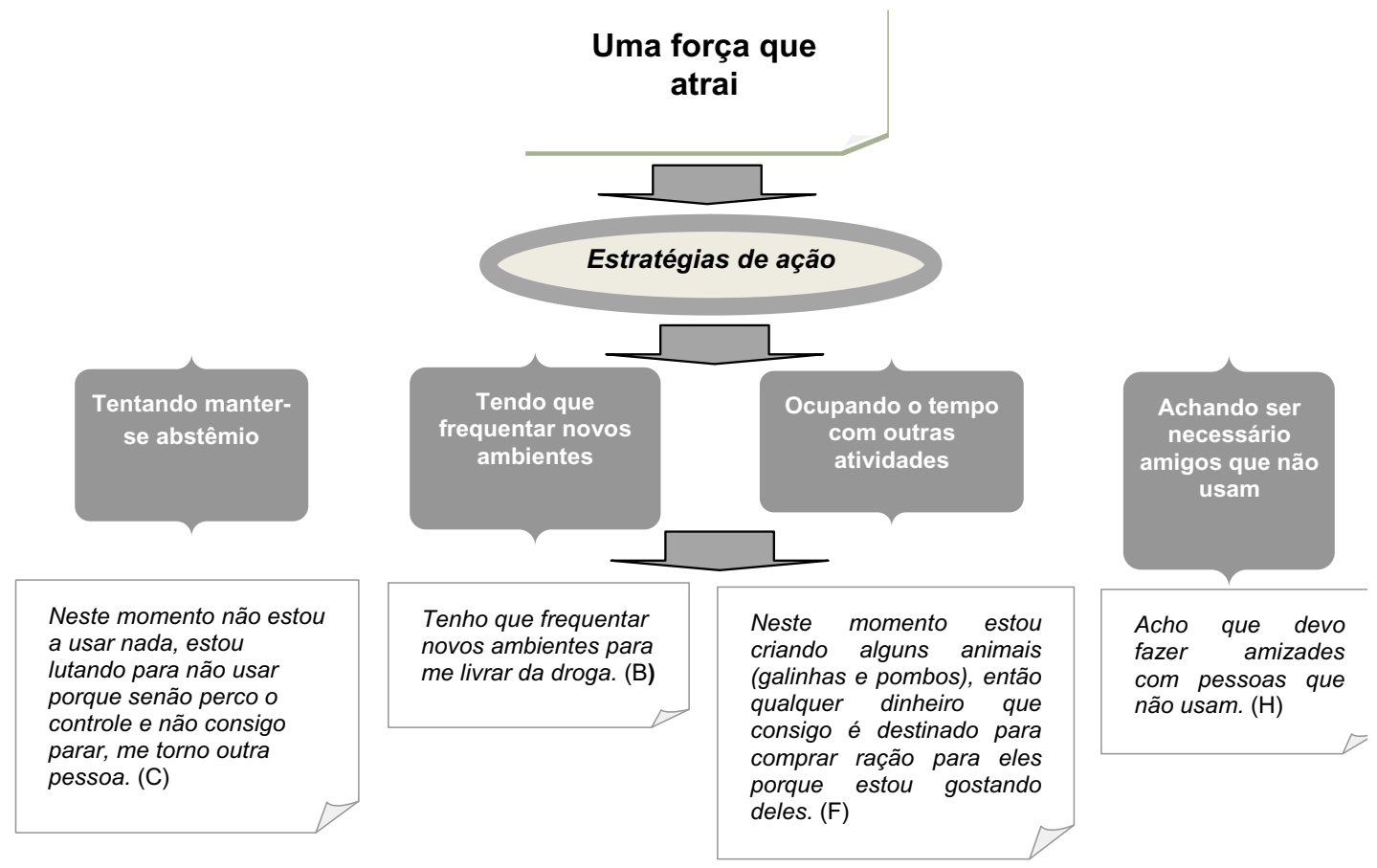

Figura 5 - Diagrama das estratégias de ação frente ao fenômeno "uma força que atrai"

\section{Discussão}

A análise dos dados possibilitou identificar que o usuário de drogas vivencia um processo caracterizado pela dificuldade de afastar-se da substância, apesar de conhecer as consequências de seu uso e, nesse contexto, visualiza a droga como "uma força que atrai".

Em seus relatos, os usuários mencionam, como causas para o consumo inicial, o fato de se sentirem inúteis, a necessidade de esquecer os problemas e sesentirem mais leves, bem como a influência do grupo de amigos. Observa-se, assim, que a droga entra na vida do indivíduo como possibilidade de fuga das dificuldades e de satisfação plena, sendo que a imediata e intensa sensação de prazer ou ausência de desprazer suscita novo uso. O encontro com as drogas transforma o modo como o usuário se sente, alcançando possibilidades antes desconhecidas ou apenas suspeitadas, de modo que passa a valorizar tais substâncias como via de acesso a um viver mais agradável e suportável(10-11).

A interação social também determina a construção de significados e ações deles resultantes, pois pôdese perceber, nas narrativas, que o primeiro contato com as drogas se deu por influência de amigos, pela necessidade do pertencer ao grupo. Assim, é possível compreender o uso das drogas como intrinsecamente ligado a um contexto de interações simbólicas que gera e faz circular conhecimentos sobre a mesma e que vai servir de guia para o consumidor. Esse contexto remete à reflexão de que a droga existe independente do usuário; o seu consumo só é possível com a participação do indivíduo; o uso, o abuso ou a dependência só podem ser definidos a partir da relação triangular entre o sujeito, a droga e o contexto em que essa droga é consumida(12).

Frente à dificuldade para se afastar das drogas, o usuário vivencia perdas nas diferentes esferas de sua vida. Destaca-se o fato de cinco participantes do estudo terem perdido o emprego como consequência do uso de drogas. Estudo(13) aponta a atividade laboral como importante fator de proteção para o uso de drogas. $\mathrm{Na}$ esfera afetiva, vivencia perdas nas relações com amigos e familiares. A esse respeito, a literatura aponta que geralmente o usuário de drogas nunca formou uma família ou tem dificuldade para sustentar o funcionamento da 
estrutura familiar, devido, principalmente, a problemas na regulação das relações e dos afetos, pois ele tende a substituir o relacionar-se com pessoas por um relacionarse com a substância de abuso(14).

Na voz dos sujeitos desse estudo, a família aparece como fator interveniente que pode tanto contribuir para o consumo da droga, quando não apoia seu membro usuário ou o "rejeita", como pode ser fator protetor quando o "ajuda". De acordo com estudo sobre a temática, a baixa qualidade na relação familiar pode gerar ambiente facilitador ao uso da droga. Entretanto, tem função preventiva a família na qual o diálogo com os pais existe(15).

O cenário familiar é contexto de construção de práticas culturais, de modo de olhar e de agir, engendrado em uma intrincada rede de símbolos e significados(16). A família, assim, desempenha papel fundamental na transmissão e disseminação de valores, cujas transformações, recebidas por meio da educação formal e informal são gradualmente processadas e remodeladas, permitindo ao indivíduo, a elaboração de uma visão do mundo e de como inserir-se na sociedade.

Os estudos apontam para a complexa influência da família, da escola e do grupo de amigos no caso da manifestação do uso abusivo de drogas, sendo indispensável o tratamento do sistema familiar para a transformação do uso abusivo em produção de saúde(14).

Frente ao contexto, já descrito, de perdas nas diversas esferas do cotidiano, o usuário adota estratégias para afastar-se das drogas. Dentre tais estratégias destacam-se a iniciativa de lutar contra as drogas, tentando manter-se abstêmio, a busca por amigos não usuários em novos ambientes, bem como a tentativa de ocupar seu tempo com outras atividades que Ihe proporcionem prazer. Estudo(14) sobre a temática evidencia que quanto maior o suporte que um usuário possa reunir maiores são as chances de manutenção da abstinência e de mudanças de comportamento. Acreditase que o conhecimento das experiências vividas pelos usuários de drogas, por meio de fonte relevante, o discurso deles, permita a elaboração e implementação de programas de prevenção efetivos que considerem sua subjetividade.

\section{Considerações Finais}

Este estudo permitiu compreender, no próprio discurso daquele que faz uso de drogas, o significado da substância em sua vida e o tipo de relação que esse indivíduo estabelece com a mesma, permitindo identificar pontos vulneráveis (fatores de risco/proteção) de possível atuação de equipes multidisciplinares, visando a prevenção do abuso de drogas.

Uma intervenção de sucesso, pela equipe multidisciplinar, na comunidade estudada, deve estar orientada pelos significados socialmente atribuídos às drogas, devendo ser apoiada no contexto e condições causais identificados, nas consequências do consumo para o indivíduo e nos fatores considerados como intervenientes para o desencadeamento e manutenção do uso. Deve-se, ainda, buscar reforçar as estratégias positivas adotadas pelos usuários, frente ao significado atribuído à substância. É de fundamental importância o planejamento de ações de saúde frente ao consumo de drogas, ponderando que essas ações podem ser eficazes se orientadas por significados construídos pela própria comunidade.

\section{Agradecimentos}

Agradecemos a Comissão Interamericana para o Controle do Abuso de Drogas/CICAD da Secretaria de Segurança Multidimensional/SSM da Organização dos Estados Americanos/OEA, a Secretaria Nacional de Políticas sobre Drogas/SENAD do Gabinete de Segurança Institucional/Brasil, a Escola de Enfermagem de Ribeirão Preto da Universidade de São Paulo e o Centro Colaborador da Organização Mundial da Saúde para o Desenvolvimento da Pesquisa em Enfermagem, a população representada nas pesquisas, bem como as autoridades das universidades representadas pelos participantes do Programa On-Line de Especialização em Pesquisa sobre o Fenômeno das Drogas - PREINVEST, períodos 2005, 2006, 2007 e 2008.

\section{Referências}

1. Brusamarello T, Sureki M, Borrile D, Roehr H, Alves M. Consumo de drogas: concepções de familiares de estudantes em idade escolar. SMAD, Rev. Eletrônica Saúde Mental Álcool Drog. [internet]. 2008 [acesso em: 21 jul 2009]; 4(1). Disponível em: http://www2.eerp.usp.br/resmad/artigos/2008v4n1a03.pdf

2. Noto AR, Baptista MC, Faria ST, Napo AS, Galduróz JCF, Carlini EA. Droga e saúde na empresa brasileira: uma análise de artigos publicados em jornais e revistas. Cad Saúde Pública. 2003;19(1):69-79. 
3. Silva J, Ventura CAA, Vargens OMC, Loyola CMD, Eslava Albarracín DG, Diaz J, et al. Illicit drug use in seven Latin American countries: critical perspectives of families and familiars. Rev. Latino-Am. Enfermagem. 2009;17(spe):763-9.

4. Silveira DX. Um guia para a família. Brasília: Presidência da República, SENAD; 2000. Publicação 1, serie diálogo.

5. Laranjeira R, Coordenador. Usuários de substâncias psicoativas: abordagem, diagnóstico e tratamento. 2ed. São Paulo: Conselho Regional de Medicina do Estado de São Paulo/ Associação Médica Brasileira; 2003.

6. Werlang BSG, Borges VR, Fensterseifer L. Fatores de Risco ou Proteção para a Presença de Ideação Suicida na Adolescência. Rev Interam Psicol. 2005; 39(2):259-66.

7. Vargens OMC, Brands B, Adlaf E, Giesbrecht N, Simich L, Wright MGM. Uso de drogas ilícitas e perspectivas críticas de familiares e pessoas próximas, na cidade do Rio de Janeiro, Zona Norte, Brasil. Rev. Latino-Am. Enfermagem. 2009;17(spe):776-82.

8. Marinho MB. O demônio nos "paraísos artificiais": considerações sobre as políticas de comunicação para a saúde relacionadas ao consumo de drogas. Interface (Botucatu) 2005; 9(17):343-54.

9. Strauss A, Corbin J. Basics of qualitative research: grounded theory, procedures and techniques. Newbury Park: Sage; 1990. 10. Sipahi FM, Vianna FC. Uma análise da dependência de drogas numa perspectiva fenomenológica existencial. Análise Psicol 2001; 4(19):503-7.
11. Lima IS, Paliarin MM, Zaleski EGF, Arantes SL. História oral de vida de adolescentes dependentes químicos, internados no setor de psiquiatria do hospital regional de Mato Grosso do Sul para tratamento de desintoxicação. SMAD, Rev Eletrônica Saúde Mental Álcool Drog [internet]. 2008 [acesso em: 21 jul 2009]; 4(1). Disponível em: http://www2.eerp.usp.br/resmad/ artigos/2008v4n1a02.pdf

12. Caldeira ZF. Drogas, indivíduo e família: um estudo de relações singulares. 1999. 81f. Dissertação (Mestrado). Rio de Janeiro: Escola Nacional de Saúde Pública / FIOCRUZ; 1999.

13. Carrillo PLL, Mauro MYC. O trabalho como fator de risco ou fator de proteção para o consumo de álcool e outras drogas. Texto \& Contexto Enferm. 2004;13(2):217-25.

14. Schenker M, Minayo MCS. A importância da família no tratamento do uso abusivo de drogas: uma revisão da literatura. Cad. Saúde Pública. 2004; 20(3):649-59.

15. Sanchez ZVDM, Oliveira LG, Nappo SA. Razões para o nãouso de drogas ilícitas entre jovens em situação de risco. Rev Saúde Pública. 2005; 39(4):599-605.

16. Roehrs H, Lenardt MH, Maftum MA. Práticas culturais familiares e o uso de drogas psicoativas pelos adolescentes: reflexão teórica. Esc Anna Nery Rev Enferm. 2008; 12(2):353-7. 